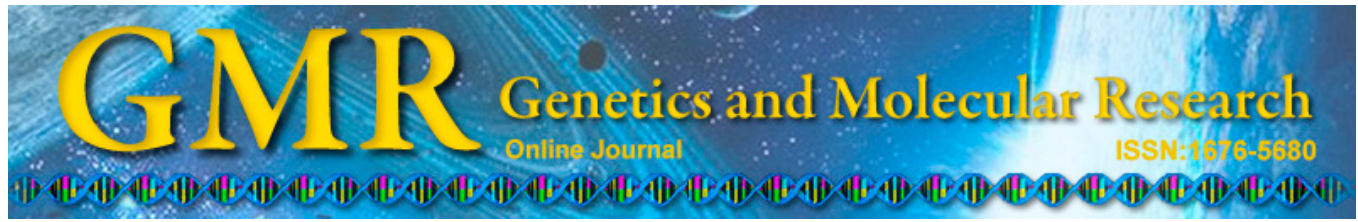

\title{
MCP-1 gene polymorphisms in North Chinese patients with pulmonary tuberculosis
}

\author{
G.L. Shi, L. Yang, Y. Sun, Y.J. Yin and C.X. Song \\ Department of Clinical Immunology Laboratory, \\ Beijing Tuberculosis and Thoracic Tumor Research Institute, Beijing, China \\ Corresponding author: C.X. Song \\ E-mail: songchangx@sina.com
}

Genet. Mol. Res. 14 (2): 4035-4040 (2015)

Received July 10, 2014

Accepted November 24, 2014

Published April 27, 2015

DOI http://dx.doi.org/10.4238/2015.April.27.18

\begin{abstract}
Pulmonary tuberculosis (PTB) remains one of the most important infectious diseases worldwide. Several studies have suggested that genetic factors may affect the susceptibility to PTB, but the specific genes involved have not been fully characterized. The gene for monocyte chemoattractant protein $1(M C P-1)$ has been linked to an increased risk of tuberculosis in some Mexican and Korean populations. To explore the role of the $M C P-1$ gene in the susceptibility to PTB in a North Chinese population, we evaluated the association between MCP-1 -2518A/G gene polymorphisms and the risk for tuberculosis. Polymerase chain reaction amplification of genomic DNA followed by restriction fragment length polymorphism analysis was used. There was a significant increase in the frequency of the GG genotype of $M C P-1$ -2518 in 136 patients with PTB compared to that in 152 healthy controls $\left(\mathrm{P}=0.008, \chi^{2}=7.133\right.$, odds ratio $\left.=1.96\right)$. Similarly, the frequencies of the A/G alleles in the 2 groups differed; the frequency of allele $\mathrm{G}$ was higher in patients with $\mathrm{PTB}\left(\mathrm{P}=0.011, \chi^{2}=6.428\right.$, odds ratio $=$ 1.536). In conclusion, the $-2518 \mathrm{~A} / \mathrm{G}$ polymorphism in the $M C P-1$ gene
\end{abstract}


was found to be associated with an increased susceptibility to PTB in a North Chinese population.

Key words: Genetic polymorphism; Pulmonary tuberculosis; Monocyte chemoattractant protein 1

\section{INTRODUCTION}

Tuberculosis (TB) is a serious health problem with an estimated 8-10 million new cases per year worldwide, resulting in 1-2 million deaths every year (Elbam, 2008). The population in China faces a high burden of TB. TB is a chronic infectious disease that is mainly caused by Mycobacterium tuberculosis. It is estimated that approximately one-third of the world's population is infected with M. tuberculosis (World Health Organization, 2006), but only $5-10 \%$ of those infected will develop a clinical disease, indicating the existence of host factors regulating disease expression (Bellamy, 1998; Frieden et al., 2003). In addition, twin studies have shown an increased concordance rate among monozygotic compared to dizygotic twins, indicating the importance of host genetic factors in the development of TB (Leandro et al., 2009). In fact, a large number of single-nucleotide polymorphisms in various genes have reported to be associated with the development of TB, such as the polymorphisms of the HLA haplotype, vitamin $\mathrm{D}_{3}$ receptor, and SCL11A1, among others (Bellamy, 2003; Fernando and Britton, 2006). Thus, identifying host genetic factors for susceptibility to TB would greatly aid the global control of this disease.

Monocyte chemoattractant protein 1 (MCP-1) is an important chemokine and was the third chemokine to be purified to homogeneity after platelet factor 4 and interleukin-8 (Matsushima et al., 1989). MCP-1 has 76 amino acid residues and its gene is located on 17q11.2-q12 (Rollins et al., 1991). This chromosomal region has been linked to the susceptibility to TB and contains genes that encode for several chemokines that may contribute to immunity against TB (Jamieson et al., 2004). It has been demonstrated that $M C P-1$ is related to pulmonary tuberculosis (PTB) in Mexicans and Koreans (Flores-Villanueva et al., 2005). However, the genetic associations between $M C P-1-2518 \mathrm{~A} / \mathrm{G}$ polymorphisms and PTB in North China have not been reported.

In the study, we examined the $M C P-1-2518 \mathrm{~A} / \mathrm{G}$ polymorphisms in 136 unrelated patients with PTB and 152 unrelated healthy controls of Han nationality in North China using polymerase chain reaction-restriction fragment length polymorphisms (PCR-RFLP). The aim of the study was to investigate the role of $M C P-1-2518 \mathrm{~A} / \mathrm{G}$ polymorphisms in the genetic susceptibility to PTB.

\section{MATERIAL AND METHODS}

\section{Subjects}

The study used a case-control design to compare healthy controls and patients with PTB. The study enrolled 136 unrelated patients with PTB of Han nationality from North China. All patients were registered in the Respiratory Department of the Beijing Tuberculosis Research Institute between October 2009 and February 2011. Patients clinically and radiologically diagnosed with PTB and confirmed by sputum smear and culture for Mycobacterium 
TB were included. All patients were human immunodeficiency virus-negative, and none presented with other infections, diseases, or immunosuppressive conditions. A total of 152 controls were unrelated healthy people of Han nationality from North China who had no history of TB and no evidence of prior TB noted on chest radiograph. All subjects gave informed consent for the study.

\section{$M C P-1$ genotyping}

Genomic DNA from patients and controls was extracted from peripheral blood leukocytes using standard methods (Davis et al., 1980; Miller et al., 1988). The MCP-1-2518 A/G polymorphism was genotyped by PCR-RFLP. The PCR system contained 2 U Taq DNA polymerase, $5 \mu \mathrm{L}$ 10X PCR buffer, $5 \mu \mathrm{L}$ loading dye, $5 \mu \mathrm{L}$ stabilizer, $2 \mu \mathrm{L}$ DNA, $2 \mu \mathrm{L}$ of each forward and reverse primers, and $30 \mu \mathrm{L}$ pure water. PCR primer sequences were: forward primer 5'-TTCTCTTCTACGGGATCTGGG-3', reverse primer 5'-GTCTCTCCTGGCTTAGT CAT-3'. PCRs were performed under the following conditions: 1 cycle of denaturation at $95^{\circ} \mathrm{C}$ for $3 \mathrm{~min}$; followed by 35 cycles at $94^{\circ} \mathrm{C}$ for $40 \mathrm{~s}, 59^{\circ} \mathrm{C}$ for $40 \mathrm{~s}$, and $74^{\circ} \mathrm{C}$ for $40 \mathrm{~s}$; and a final extension step at $72^{\circ} \mathrm{C}$ for $4 \mathrm{~min}$. PCR products $(10 \mu \mathrm{L})$ were digested for $16 \mathrm{~h}$ by $P v u \mathrm{II}$ in a final volume of $20 \mu \mathrm{L}$ that contained $10 \mathrm{X}$ enzyme buffer. The resulting fragments were separated by electrophoresis on 3\% ethidium bromide-stained agarose gel and were visualized under ultraviolet light. The PCR products were 466-bp fragments, which contained a unique $P v u \mathrm{II}$ restriction site. This site was intact if $\mathrm{G}$ was at position -2518. $P v u \mathrm{II}$ digests the 466-bp DNA segment from G/G homozygous individuals into 327- and 139-bp fragments. The DNA segment from G/A heterozygous individuals yielded 466-, 327-, and 139bp fragments. PCR products from A/A homozygous individuals were not cut with $P v u I I$, yielding only one 466-bp fragment.

\section{Statistical analysis}

Allele and genotype frequencies were calculated by direct counting. Hardy-Weinberg equilibrium was assessed using the $\chi^{2}$ test. Differences in the frequencies of alleles or genotypes between the different groups were estimated using the $\chi^{2}$ test or the Fisher exact test. A 2 -sided $\mathrm{P}<0.05$ was considered to be statistically significant, and odds ratios (ORs) with $95 \%$ confidence intervals (CIs) were also calculated for comparisons showing significant $P$ values. All statistical analyses were conducted using SPSS version 17.0 program (SPSS, Inc.; Chicago, IL, USA).

\section{RESULTS}

\section{Demographics of the subjects}

The study participants included 136 patients with PTB and 152 healthy controls. Their baseline characteristics are summarized in Table 1.

\section{Genotypes and alleles of $M C P-1$ in patients with $\mathrm{PTB}$ and controls}

The distributions of the AA, AG, and GG genotypes of $M C P-1-2518$ did not deviate 
from Hardy-Weinberg equilibrium $(\mathrm{P}>0.05)$ in patients with PTB and controls. There was a significant increase in the frequency of the GG genotype in patients with PTB compared to controls $\left(\mathrm{P}<0.05, \chi^{2}=7.133\right.$, OR $\left.=1.96\right)$. The frequency of the $\mathrm{AA}$ and $\mathrm{AG}$ genotypes of $M C P-1-2518$ did not differ between patients with PTB and controls $(\mathrm{P}>0.05)$. The frequency of the $\mathrm{A} / \mathrm{G}$ alleles in the 2 groups was also different; the frequency of allele $\mathrm{G}$ was higher in patients with PTB $\left(\mathrm{P}<0.05, \chi^{2}=6.428, \mathrm{OR}=1.536\right)$ (Table 2$)$.

\begin{tabular}{lcc}
\multicolumn{2}{c}{ Table 1. Demographic and clinical characteristics of subjects. } \\
\hline \\
\hline PTB N $=136$ & Control N = 152 \\
\hline Age (years) median (range) & $36(18-56)$ & $30(21-50)$ \\
Gender (M/F) & $61 / 75$ & $68 / 84$ \\
Pulmonary tuberculosis & 136 & \\
Culture proven & $66(48.5 \%)$ & \\
Pathological diagnosed & $70(51.5 \%)$ & \\
Drug sensitive & $88(64.7 \%)$ & \\
Drug resistant & $48(35.3 \%)$ & \\
Initial treatment & $93(68.4 \%)$ & \\
Retreatment & $43(31.6 \%)$ &
\end{tabular}

Table 2. Alleles and genotypes of $M C P-1$ in patients with pulmonary tuberculosis (PTB) and controls.

\begin{tabular}{llcccc}
\hline & PTB & Control & $\chi^{2}$ & P & OR (95\%CI) \\
\hline AA & $16.9(23 / 136)$ & $23.1(35 / 152)$ & 1.669 & 0.196 & \\
GG & $41.2(56 / 136)$ & $26.3(40 / 152)$ & 7.133 & 0.008 & $1.96(1.192-3.222)$ \\
AG & $41.9(57 / 136)$ & $50.6(77 / 152)$ & 2.207 & 0.137 & \\
A & $37.9(103 / 272)$ & $48.3(147 / 304)$ & 6.428 & 0.011 & $0.651(0.467-0.908)$ \\
G & $62.1(169 / 272)$ & $51.7(157 / 304)$ & 6.428 & 0.011 & $1.536(1.102-2.142)$ \\
\hline
\end{tabular}

\section{Genotypes and alleles of $M C P-1$ in patients with PTB}

The frequency of the AA, AG, and GG genotypes and the A and $\mathrm{G}$ alleles of the $M C P-1-2518$ gene did not differ between drug-sensitive patients with PTB and drug-resistant patients $(\mathrm{P}>0.05)$ (Table 3$)$. The frequency of the $\mathrm{AA}, \mathrm{AG}$, and $\mathrm{GG}$ genotypes and the $\mathrm{A}$ and $\mathrm{G}$ alleles of the $M C P-1-2518$ gene did not differ between initial treatment patients with PTB and retreatment patients $(\mathrm{P}>0.05)$ (Table 4).

Table 3. Alleles and genotypes of $M C P-1$ in drug sensitive and drug resistant patients with pulmonary tuberculosis

\begin{tabular}{lccccc}
\hline & AA & GG & AG & A & G \\
\hline Drug sensitive & $18.2(16 / 88)$ & $38.6(34 / 88)$ & $43.2(38 / 88)$ & $39.8(70 / 176)$ & $60.2(106 / 176)$ \\
Drug resistant & $14.6(7 / 48)$ & $45.8(22 / 48)$ & $39.6(19 / 48)$ & $34.4(33 / 96)$ & $65.6(63 / 96)$ \\
$\chi^{2}$ & 0.286 & 0.593 & 0.165 & 0.769 & 0.769 \\
$\mathrm{P}$ & 0.495 & 0.415 & 0.684 & 0.38 & 0.38 \\
\hline
\end{tabular}

Table 4. Alleles and genotypes of $M C P-1$ in initial treatment and retreatment patients with pulmonary tuberculosis.

\begin{tabular}{lccccc}
\hline & AA & GG & AG & A & G \\
\hline Initial treatment & $18.3(17 / 93)$ & $39.8(37 / 93)$ & $41.9(39 / 93)$ & $33.9(63 / 186)$ & $66.1(123 / 186)$ \\
Retreatment & $13.9(6 / 43)$ & $44.2(19 / 43)$ & $41.9(18 / 43)$ & $34.9(30 / 86)$ & $65.1(56 / 86)$ \\
$\chi^{2}$ & 0.392 & 0.235 & 0.000 & 0.027 & 0.027 \\
$\mathrm{P}$ & 0.531 & 0.628 & 0.993 & 0.87 & 0.87 \\
\hline
\end{tabular}




\section{DISCUSSION}

It is well known that approximately one-third of the world's population is infected with M. tuberculosis. However, $90 \%$ of infected individuals remain healthy, indicating the effectiveness of the different immune mechanisms in the resistance against this Mycobacterium. Although both acquired and innate mechanisms contribute to the killing of M. tuberculosis, the precise mechanisms that confer resistance against this infection are not fully understood. Nevertheless, it seems evident that different genes are involved in the susceptibility to Mycobacterium TB infection (Kramnik et al., 2000; Delgado et al., 2002). The functional significance of the MCP-1 chemokine in attracting monocytes to the site of infectious lesions and its presumed role in the pathogenesis of tuberculosis and the granulomatous response suggests that variations in the $M C P-1$ gene participate in the susceptibility to or protection against tuberculosis. In the study, we explored the association between the $-2518 \mathrm{~A} / \mathrm{G}$ polymorphisms in the $M C P-1$ gene and PTB in a Han population from North China.

We found a significant increase in the frequency of the GG genotype in patients with PTB compared to in controls $(\mathrm{P}=0.008, \mathrm{OR}=1.96,95 \% \mathrm{CI}=1.192-3.222)$. Similarly, the frequency of the $\mathrm{A} / \mathrm{G}$ alleles in the 2 groups also differed; the frequency of allele $\mathrm{G}$ was higher in patients with $\mathrm{PTB}(\mathrm{P}=0.011, \mathrm{OR}=1.536,95 \% \mathrm{CI}=1.102-2.142)$. In contrast, the frequency of the AA, AG, and GG genotypes and the A and $\mathrm{G}$ alleles of the $M C P-1-2518$ gene did not differ between drug-sensitive patients with PTB and drug-resistant patients $(\mathrm{P}>0.05)$. The frequency of the AA, AG, and GG genotypes and the A and $\mathrm{G}$ alleles of the $M C P-1-2518$ gene did not differ between initial treatment patients with PTB and retreatment patients $(\mathrm{P}>0.05)$.

Several studies have reported the association between $M C P-1-2518 \mathrm{~A} / \mathrm{G}$ polymorphisms and tuberculosis risk, but the results have been inconsistent in different populations. The results of the study are consistent with those of previous reports regarding the association between $M C P-1-2518 \mathrm{~A} / \mathrm{G}$ polymorphisms and tuberculosis in Mexicans, Koreans, Peruvians, Tunisians, and Zambians (Flores-Villanueva et al., 2005; Buijtels et al., 2008; Ganachari et al., 2010; Ben-Selma et al., 2011). Others have reported different results, such as in South African Coloreds, Indians, and Ghanaians (Alagarasu et al., 2009; Moller et al., 2009; Thye et al., 2009). Different genetic backgrounds may account for these differences. In addition, PTB is a complex disease that results from the infection with Mycobacterium TB and genetic susceptibility. These differences in genetic susceptibility may also result from individual status or other factors (Zhang et al., 2010). Thus, further studies are needed to assess the effect of additional interactions in different ethnicities and to validate our results. The molecular mechanism of the association between the $M C P-1$ gene and PTB may be that the MCP-1 is a potent chemotactic factor for monocytes (Flores-Villanueva et al., 2005; Ben-Selma et al., 2011), which plays critical roles in the recruitment of macrophages and T lymphocytes for controlling the dissemination of Mycobacterium TB (Xu et al., 2009). The $-2518 \mathrm{~A} / \mathrm{G}$ polymorphism in the $M C P-1$ regulatory region influences the levels of $M C P-1$ expression in response to inflammatory stimuli. The G allele of $M C P-1$ may be the allele associated with a higher $M C P-1$ expression in certain inflammatory conditions (Tumgor et al., 2008).

In conclusion, we examined the association between $-2518 \mathrm{~A} / \mathrm{G}$ polymorphisms in the $M C P-1$ gene and PTB. Our results suggest that the $-2518 \mathrm{~A} / \mathrm{G}$ polymorphisms in the $M C P-1$ gene are associated with an increased susceptibility to PTB in our North Chinese population. However, because of the relatively small number of patients and the possibility of racial differences, further investigation using a larger sample size is necessary to confirm the present findings. 


\section{ACKNOWLEDGMENTS}

We are grateful to patients and controls who took part in this investigation. The study was supported by Beijing Tuberculosis and Thoracic Tumor Research Institute.

\section{REFERENCES}

Alagarasu K, Selvaraj P, Swaminathan S, Raghavan S, et al. (2009). CCR2, MCP-1, SDF-1a \& DC-SIGN gene polymorphisms in HIV-1 infected patients with \& without tuberculosis. Indian J. Med. Res. 130: 444-450.

Bellamy R (1998). Genetics and pulmonary medicine. 3. Genetic susceptibility to tuberculosis in human populations. Thorax 53: 588-593.

Bellamy R (2003). Susceptibility to mycobacterial infections: the importance of host genetics. Genes Immun. 4: 4-11.

Ben-Selma W, Harizi H and Boukadida J (2011). MCP-1-2518 A/G functional polymorphism is associated with increased susceptibility to active pulmonary tuberculosis in Tunisian patients. Mol. Biol. Rep. 38: 5413-5419.

Buijtels PC, van de Sande WW, Parkinson S, Petit PL, et al. (2008). Polymorphism in CC-chemokine ligand 2 associated with tuberculosis in Zambia. Int. J. Tuberc. Lung Dis. 12: 1485-1488.

Davis RW, Thomas M, Cameron J, St John TP, et al. (1980). Rapid DNA isolations for enzymatic and hybridization analysis. Methods Enzymol. 65: 404-411.

Delgado CJ, Baena A, Thim S and Goldfeld AE (2002). Ethnic-specific genetic associations with pulmonary tuberculosis. J. Infect. Dis. 186: 1463-1468.

Elbam I (2008). Susceptibility to and severity of tuberculosis is genetically controlled by human leukocyte antigens. Saudi Med. J. 29: 1625-1629.

Fernando SL and Britton WJ (2006). Genetic susceptibility to mycobacterial disease in humans. Immunol. Cell Biol. 84: 125-137.

Flores-Villanueva PO, Ruiz-Morales JA, Song CH, Flores LM, et al. (2005). A functional promoter polymorphism in monocyte chemoattractant protein-1 is associated with increased susceptibility to pulmonary tuberculosis. $J$. Exp. Med. 202: 1649-1658.

Frieden TR, Sterling TR, Munsiff SS, Watt CJ, et al. (2003). Tuberculosis. Lancet 362: 887-899.

Ganachari M, Ruiz-Morales JA, de la Torre JCG, Dinh J, et al. (2010). Joint effect of MCP-1 genotype GG and MMP-1 genotype 2G/2G increases the likelihood of developing pulmonary tuberculosis in BCG-vaccinated individuals. PLoS One 5: e8881.

Jamieson SE, Miller EN, Black GF, Peacock CS, et al. (2004). Evidence for a cluster of genes on chromosome 17q11-q12 controlling susceptibility to tuberculosis and leprosy in Brazilians. Genes Immun. 5: 46-57.

Kramnik I, Dietrich WF, Demant P and Bloom BR (2000). Genetic control of resistance to experimental infection with virulent Mycobacterium tuberculosis. Proc. Natl. Acad. Sci. USA 97: 8560-8565.

Leandro AC, Rocha MA, Cardoso CS and Bonecini-Almeida MG (2009). Genetic polymorphisms in vitamin D receptor, vitamin D-binding protein, Toll-like receptor 2, nitric oxide synthase 2, and interferon-gamma genes and its association with susceptibility to tuberculosis. Braz. J. Med. Biol. Res. 42: 312-322.

Matsushima K, Larsen CG, DuBois GC and Oppenheim JJ (1989). Purification and characterization of a novel monocyte chemotactic and activating factor produced by a human myelomonocytic cell line. J. Exp. Med. 169: 1485-1490.

Miller SA, Dykes DD and Polesky HF (1988). A simple salting out procedure for extracting DNA from human nucleated cells. Nucleic Acids Res. 16: 1215.

Moller M, Nebel A, Valentonyte R, van Helden PD, et al. (2009). Investigation of chromosome 17 candidate genes in susceptibility to TB in a South African population. Tuberculosis 89: 189-194.

Rollins BJ, Morton CC, Ledbetter DH, Eddy RL Jr., et al. (1991). Assignment of the human small inducible cytokine A2 gene, SCYA2 (encoding JE or MCP-1), to 17q11.2-q12: evolutionary relatedness of cytokines clustered at the same locus. Genomics 10: 489-492.

Thye T, Nejentsev S, Intemann CD, Browne EN, et al. (2009). MCP-1 promoter variant- 362C associated with protection from pulmonary tuberculosis in Ghana, West Africa. Hum. Mol. Genet. 18: 381-388.

Tumgor G, Berdeli A, Arikan C, Levent E, et al. (2008). Mcp-1, eNOS, tPA and PAI-1 gene polymorphism and correlation of genotypes and phenotypes in hepatopulmonary syndrome. Dig. Dis. Sci. 53: 1345-1351.

World Health Organization (2006). Global tuberculosis control: surveillance, planning, financing. World Health Organization Report 2006 (WHO/HTM/TB/ 2006362), Beijing, China.

Xu ZE, Xie YY, Chen JH, Xing LL, et al. (2009). Monocyte chemotactic protein-1 gene polymorphism and monocyte chemocactic protein-1 expression in Chongqing Han children with tuberculosis. Zhonghua Erke Zazhi 47: 200-203.

Zhang YG, Li XB, Zhang J, Huang J, et al. (2010). The I/D polymorphism of angiotensin-converting enzyme gene and asthma risk: a meta-analysis. Allergy 66: 197-205. 